\title{
O USO DA TRIANGULAÇÃO EM TESES E DISSERTAÇÕES DE PROGRAMAS DE PÓS-GRADUAÇÃO EM ADMINISTRAÇÃO NO BRASIL
}

\author{
THE USE OF TRIANGULATION IN THESES AND DISSERTATIONS OF \\ POSTGRADUATE PROGRAMS IN BUSINESS ADMINISTRATION IN BRAZIL
}

\author{
Recebido em: 14/11/2017 • Aprovado em: 17/04/2018 \\ Avaliado pelo sistema double blind review \\ Editor Científico: Edson Sadao Iizuka \\ DOI 10.13058/raep.2018.v19n2.853
}

\section{ALFREDO RIBEIRO CÁRDENAS alfredo.ribeiro@ifsc.edu.br}

Instituto Federal de Santa Catarina

\section{TIAGO DA COSTA}

Universidade Federal da Fronteira Sul

\section{GRAZIELA DIAS ALPERSTEDT \\ SIMONE GHISI FEUERSCHÜTTE}

\author{
Universidade do Estado de Santa Catarina
}

\begin{abstract}
RESUMO
O uso da triangulação em estudos qualitativos na área da Administração tem sido visto como um procedimento relacionado ao rigor metodológico e incremento da qualidade de pesquisas, incluindo teses e dissertações. Não obstante, devido às diversas possibilidades de emprego, a concepção e prática da triangulação aparentam ainda não estar completamente compreendidas. Nesse sentido, este estudo teve como objetivo identificar, analisar e exemplificar o uso da triangulação em teses e dissertações da área da Administração no Brasil. Com base nos trabalhos encontrados no banco de teses e dissertações da Capes, foi realizada a análise dos trabalhos, buscando identificar as metodologias empregadas nos estudos e, posteriormente, analisar e exemplificar a utilização dos diferentes tipos de triangulação nas pesquisas encontradas. Os resultados demonstram ser possível encontrar, no escopo de teses e dissertações brasileiras da área da administração, a utilização de todas as tipologias (entre métodos, intramétodo, de dados, de teorias e de pesquisadores) presentes na literatura, com predomínio da triangulação entre métodos. Porém identificou-se uso escasso da triangulação de teorias. Conclui-se que a triangulação é um procedimento que tem contribuído com o rigor científico, em teses e dissertações, assim, possibilitado a ampliação do entendimento de diversos temas e fenômenos na área da Administração no país.

Palavras-chave: Triangulação. Métodos de Pesquisa. Pesquisa Qualitativa.
\end{abstract}

\begin{abstract}
The use of triangulation in qualitative studies in the field of Business Administration has been seen as a procedure related to methodological rigor for increasing the quality of research, including theses and dissertations. Nevertheless, due to the diverse possibilities of employing it, the design and practice of triangulation appear to be still not fully understood. In this sense, this study aimed to identify, analyze and bring examples of the use of triangulation in theses and dissertations in the field of Business Administration in Brazil. After a search in the thesis and dissertations database of CAPES, the works found were analyzed, initially aiming to identify the methodologies used in those studies and later seeking to analyze and bring examples o the use of the different types of triangulation. The results show that it is possible to find, within the scope of Brazilian theses and dissertations in the field of Business Administration, the use of all typologies (among methods, intra-method, data, of theories and researchers) present in the literature, with a predominance of triangulation between methods. On the other hand, a scarce use of triangulation of theories was identified. It is concluded that triangulation is a procedure that has contributed to the scientific rigor in theses and dissertations and allowed the widening of the understanding of various themes and phenomena in the field of Business Administration in the country. Keywords: Triangulation. Research Methods. Qualitative Research.
\end{abstract}




\section{INTRODUÇÃO}

Ao longo dos tempos, tem-se evidenciado uma preocupação da comunidade científica quanto à qualidade e relevância dos estudos realizados nas diversas áreas do conhecimento. Em se tratando de pesquisa qualitativa e, especificamente, na área da Administração, requisitos como confiabilidade, validade e credibilidade repercutem na busca por um padrão de qualidade que contribua para o desenvolvimento do campo.

Nesse panorama, o uso da triangulação é visto como um procedimento voltado ao rigor metodológico e ao incremento da qualidade de pesquisas qualitativas (FLICK, 2009a; ABDALLA et al., 2018). Não obstante, devido às diversas possibilidades de emprego e, inclusive, considerando o próprio entendimento sobre o que é e o que não é triangulação - dado que tal entendimento passou por mudanças ao longo do tempo--, a concepção e a prática da triangulação ainda não são integralmente compreendidas (ZAPPELLINI; FEUERSCHÜTTE, 2015).

A visão quanto ao uso e benefícios da triangulação foi ampliada, passando de um procedimento associado a diferentes métodos de coleta de dados para um recurso mais abrangente, que considera a possibilidade de triangular fontes de dados, pesquisadores, teorias, entre outras questões, que são explicadas e exemplificadas neste trabalho. Independentemente do tipo empregado, o uso da triangulação na pesquisa qualitativa objetiva, fundamentalmente, abrandar eventuais deficiências, insuficiências e omissões que advêm da utilização de um método de coleta único, uma única fonte de dados, etc. (FLICK, 2009a).

Assim, voltando ao contexto da Administração, estudos têm demonstrado a atenção de pesquisadores da área com a questão da triangulação, apontando diferentes aspectos sobre o tema, como, por exemplo: a triangulação entre métodos gerando "meras convergências" ou "conversações paradigmáticas" na pesquisa em Administração (TEIXEIRA; NASCIMENTO; CARRIERI, 2012); o perfil dos estudos que utilizam triangulação metodológica nos anais do Encontro Nacional de Pós-Graduação em Administração e Contabilidade (TEIXEIRA; NASCIMENTO; ANTONIALLI, 2013); 
a triangulação e sua proximidade com o pragmatismo (AZEVEDO et al., 2013); e o uso da triangulação em artigos na pesquisa científica brasileira da área (ZAPPELLINI; FEUERSCHÜTTE, 2015).

Este artigo teve o propósito de avançar nessa direção, para tanto, buscando a possibilidade de analisar o uso da triangulação em teses e dissertações produzidas nos programas de pós-graduação em Administração do país. Considerando que, com frequência, artigos científicos são produtos parciais provenientes de teses e dissertações e que, segundo Azevedo et al. (2013) e Abdalla et al., (2018), grande parte dos cursos de pós-graduação não prepara os estudantes para o emprego combinado de multimétodos, um estudo com o escopo de tais trabalhos científicos pode proporcionar resultados que suportem ou contradigam as conclusões já estabelecidas em outras investigações sobre o tema.

Nesse sentido, alinhado ao entendimento e aos argumentos concatenados até aqui, este estudo teve como objetivo identificar, analisar e exemplificar o uso da triangulação em teses e dissertações da área da Administração no Brasil. Buscou-se, como resultado deste trabalho, apoiar, na forma de um recurso educacional, os programas de graduação e pós-graduação em Administração que abordem a temática da triangulação, em pesquisas qualitativas.

Diante do objetivo proposto, o artigo está estruturado, além desta introdução, da seguinte forma: a segunda seção apresenta uma revisão dos principais conceitos e questões pertinentes ao uso da triangulação em pesquisa qualitativa; a terceira parte expõe os procedimentos metodológicos empregados na pesquisa empírica que subsidiou a elaboração do artigo; a seção quatro apresenta um diagnóstico dos procedimentos metodológicos empregados em teses e dissertações da área da administração no Brasil, discutindo e apresentado exemplos dos diferentes tipos de triangulação empregados nas pesquisas encontradas e; por fim, são apresentadas as considerações finais sobre o estudo realizado. 


\section{REVISÃO TEÓRICA}

\section{O CONCEITO}

A definição de triangulação advém de áreas de atuação técnica e profissional como agrimensura e geodésia, nas quais é usada como método de localização e estabelecimento de posições na superfície da Terra com base em outros dois pontos ou posições (FLICK, 2009a); e da navegação e topografia, em que é frequentemente entendida como um método para fixar e/ ou localizar uma posição geográfica (COX; HASSARD, 2005).

Nas ciências sociais, o termo triangulação é utilizado de uma maneira menos literal e, de certa forma, mais ambígua. Segundo Azevedo et al. (2013), pode-se considerar que, ao buscar determinado conhecimento, o pesquisador precisará posicionar-se em outros dois pontos de vista, no mínimo, a fim de ajustar a adequada distância e angulação dos conceitos e posicionar-se definitivamente após a análise das visões distintas (AZEVEDO et al., 2013). Em outras palavras, triangulação em pesquisa qualitativa está relacionada à observação de determinado ponto de análise perante, pelo menos, dois pontos de vista distintos - duas técnicas de coleta de dados, por exemplo.

A princípio, a triangulação foi conceituada como estratégia para validação dos resultados obtidos com métodos individuais (CAMPBELL; FISKE, 1959). O foco, porém, tem sido deslocado cada vez mais na direção de enriquecer e de complementar ainda mais o conhecimento e superar os potenciais epistemológicos do método individual (FLICK, 2009b).

As discussões sobre triangulação, entendida inicialmente como uma proposta multimetodológica, foram impulsionadas na década de 1970, quando Norman Denzin (1978, p. 294) apresentou uma definição mais sistemática do termo, afirmando que "[...] a triangulação é o uso de múltiplos métodos no estudo do mesmo objeto”. Apesar dessa definição inicial, diversos estudos clássicos de pesquisa qualitativa já se utilizavam anteriormente dos princípios e das práticas do que se discutiria depois com a nomenclatura de triangulação (FLICK, 2009a).

Conforme afirma Flick (2009b, p. 361) "a triangulação é utilizada para designar a combinação de diversos métodos, grupos de estudo, ambien- 
tes locais e perspectivas teóricas distintas para tratar de um fenômeno". O mesmo autor ainda afirma que, no contexto da pesquisa científica, a triangulação aconteceria quando da utilização de pelo menos dois métodos diferentes para investigar um mesmo fenômeno (FLICK, 2009a).

Ao ser abordada como uma metodologia de pesquisa, várias definições podem ser apresentadas para a triangulação e precisam ser analisadas segundo a perspectiva teórica e o próprio delineamento de pesquisa em que é aplicada. A maioria dos autores relaciona suas definições do procedimento metodológico às formas como os dados são coletados e analisados, observando a combinação de técnicas ou métodos. Outros autores definem a triangulação associando-a ao objeto ou fenômeno sob investigação, ou seja, articulando o método ao âmbito epistêmico e teórico que orienta o processo da pesquisa (ZAPELLINI; FEUERSCHÜTTE, 2015). A triangulação também contribui para a criação de métodos inventivos, equilibrando novas formas de apreender um problema com métodos tradicionais de coleta de dados (ABDALLA et al., 2018)

Apesar da possibilidade de adoção de uma perspectiva multiparadigmática na triangulação, é possível perceber uma ênfase dos estudos em administração no Brasil sob um enfoque de validação convergente ao utilizar este procedimento - com vistas à complementação de métodos para incrementar a validade e confiabilidade da pesquisa - em detrimento de reconhecê-lo como uma possibilidade de articulação paradigmática entre visões distintas da realidade e do conhecimento científico (TEIXEIRA; NASCIMENTO; CARRIERI, 2012).

Sob essa perspectiva é possível valer-se da ideia da proposta da triangulação não como uma convergência de pontos, mas sim como um cristal que reflete as externalidades, assim, criando diferentes cores, padrões, matrizes, projetando-os em diferentes direções, numa abordagem epistemológica pós-moderna (RICHARDSON, ST. PIERRE, 1994; DENZIN, LINCOLN, 2005).

O olhar pós-moderno sobre a realidade explicita que ela se configura como um todo complexo, interconectado e articulado pela interação de atores que colocam em xeque valores e padrões preestabelecidos, assim, 


\section{ALPERSTEDT \& SIMONE GHISI FEUERSCHÜTTE}

gerando externalidades perversas e, por vezes, intransponíveis nas relações sociais contemporâneas. As instituições sociais, com os seus pressupostos e práticas reguladoras, já não conseguem responder às demandas de uma sociedade multicultural, ao mesmo tempo racional e subjetiva, cujo desenvolvimento revela consequências paradoxais e contraditórias. De acordo com Kumar (1997), sob o olhar pós-moderno, a nova fronteira entre Estado e sociedade, as mudanças e a diversidade dos papéis dos grupos sociais, a questão ambiental, as relações raciais, por exemplo, são questões que desafiam a compreensão e a intervenção das ciências sociais mediante diferentes ângulos.

Para caminhar na direção de tal compreensão, então, é que se pode pensar na triangulação como um recurso metodológico que permite olhar a realidade pós-moderna fazendo uso de lentes paradigmáticas distintas, que se complementam para desvendar e produzir o conhecimento mais próximo à compreensão da complexidade das interações e dos problemas humanos. Nesse sentido, a triangulação pode ser entendida como um meio que revela as diferentes nuanças e idiossincrasias dos fenômenos sociais, assim, aproximando o pesquisador da sua realidade de pesquisa de um modo mais integral e genuíno.

Desse modo, considerando a diversidade de visões e com a finalidade de sistematizar as várias concepções de triangulação oriundas de interpretações múltiplas acerca do procedimento na literatura e sua aplicação, Zapellini e Feuerschütte (2015) propuseram o Quadro 1, que objetiva demonstrar a diversidade e a evolução dos entendimentos/conceitos/concepções de triangulação, ao longo do tempo. 
Quadro 1 Sistematização das concepções de triangulação

Autor(es) CONCEITO

Denzin (1978) Combinação de metodologias diferentes para analisar o Denzin e mesmo fenômeno, de modo a consolidar a construção Lincoln (2005) de teorias sociais.

Patton (2002) Combinação de diferentes fontes e métodos de coleta de dados.

Davidson Combinação de diferentes fontes e métodos de coleta (2005) de dados, em que a análise desses dados é feita em conjunto, e não considerando dados individuais.

Combinação de diferentes métodos, grupos de estudo, ambientes, períodos de tempo e perspectivas teóricas para lidar com um fenômeno.

Flick (2009a; Estudo de um tema e um problema de pesquisa com 2009b; 2013) base em duas perspectivas privilegiadas, assumindo diferentes visões a respeito da questão de pesquisa e combinando diferentes tipos de dados sob a mesma abordagem teórica para a produção de mais conhecimento do que seria possível com base em uma só perspectiva. Método que utiliza dados adicionais para validar ou amStake (2005; pliar as interpretações feitas pelo pesquisador, adotando 2011) diferentes percepções para esclarecer o significado por meio da repetição das observações ou interpretações.

Fonte: Zapellini e Feuerschütte (2015, p. 246).

Com base nessa sistematização, o conceito básico de triangulação apresentado por Zapellini e Feuerschütte (2015, p. 246-247) é:

[...] procedimento que combina diferentes métodos de coleta e de análise de dados, diferentes populações/sujeitos (ou amostras/objetos), diferentes perspectivas teóricas e diferentes momentos no tempo, com o propósito de consolidar suas conclusões a respeito do fenômeno que está sendo investigado. 


\section{ALPERSTEDT \& SIMONE GHISI FEUERSCHÜTTE}

Com uma compreensão preliminar acerca do método é importante definir, ainda, o que não é triangulação. Flick (2009a, p. 61) afirma que uma simples combinação de métodos não deve ser compreendida como triangulação, como, por exemplo, o uso de um método para a coleta e de outro para a análise dos dados; também, não pode ser confundido o uso exploratório de métodos qualitativos antes da pesquisa propriamente dita, a menos que tal estudo seja utilizado como uma parte "genuína e autônoma" do projeto, o que significa que dados e resultados do estudo qualitativo precisam ser parte dos resultados finais do projeto. Em síntese, como mencionado, triangulação em pesquisa qualitativa está relacionada à observação da questão de pesquisa perante, pelo menos, dois pontos de vista distintos.

\section{USO E TIPOLOGIAS}

A triangulação tem a finalidade de combinar métodos e/ ou fontes de coleta de dados qualitativos e quantitativos (entrevistas, questionários, observações e notas de campo, documentos, além de outras), assim como diferentes métodos de análise dos dados, como a análise de conteúdo, a análise de discurso, os métodos e as técnicas estatísticas descritivas e/ou inferenciais, entre outros (AZEVEDO et al., 2013).

Seu objetivo, desse modo, é contribuir não apenas para o exame do fenômeno sob o olhar de múltiplas perspectivas, mas, também, enriquecer a compreensão, assim, permitindo emergir novas ou mais profundas percepções de forma a estimular a criação de métodos inventivos e novas maneiras de capturar um problema de forma equacionada com os métodos convencionais de coleta de dados (AZEVEDO et al., 2013)

De acordo com Denzin (1978, p. 294): [...] a triangulação, ou o uso de múltiplos métodos, é um plano de ação que elevará os cientistas sociais acima de vieses pessoais resultantes de uma metodologia individual.

Vários especialistas ressaltam a conveniência da combinação de métodos devido às fragilidades encontradas em projetos que empregam apenas um (AZEVEDO et al., 2013). Ao defender a ideia de que diversas estratégias podem ser associadas a esse procedimento, Denzin (1978) caracteriza quatro tipos de triangulação, desse modo, envolvendo varie- 
dades de dados, investigadores, teorias ou metodologias, conforme apresentado no Quadro 2.

Quadro 2 Tipos de Triangulação

\begin{tabular}{cl} 
Tipo & \multicolumn{1}{c}{ Descrição } \\
Dados & $\begin{array}{l}\text { Uso de diferentes fontes de dados. Possui três subtipos: } \\
\text { (a) tempo; (b) espaço; (c) pessoa. }\end{array}$ \\
Investigador & $\begin{array}{l}\text { Emprego de vários observadores ou entrevistadores do } \\
\text { mesmo objeto. }\end{array}$ \\
Teoria & $\begin{array}{l}\text { Uso de múltiplas perspectivas teóricas e hipóteses em re- } \\
\text { lação aos mesmos objetos. }\end{array}$ \\
Metodológica & $\begin{array}{l}\text { Uso de vários métodos podendo ser: (a) dentro do méto- } \\
\text { do e (b) entre métodos }\end{array}$
\end{tabular}

Fonte: Denzin (1978, p. 295)

A triangulação de dados consiste em usar diferentes fontes de dados sem se valer de métodos distintos. Nesse caso, os dados são coletados em períodos, locais ou por meio de fontes diferentes. Denzin (1978) propôs o estudo do fenômeno sob a perspectiva de tempo, espaço e com pessoas diferentes (FLICK, 2009a; AZEVEDO, et al., 2013; ZAPELLINI, FEUERSCHÜTTE, 2015).

A triangulação de investigadores refere-se ao uso de diferentes observadores ou entrevistadores para estudar a mesma questão de pesquisa ou a mesma estrutura, de modo a detectar e minimizar eventuais vieses ou tendências do pesquisador e a possibilitar perspectivas, reflexões e análises diferentes. Assim, pessoas diferentes examinam a mesma situação e são feitas comparações de dados ou de pontos de vista. Tais comparações devem ser sistemáticas e devem dar conta da influência do pesquisador sobre o tema e os resultados da pesquisa (FLICK, 2009a; AZEVEDO et al., 2013; ZAPELLINI, FEUERSCHÜTTE, 2015).

Já na triangulação teórica o investigador recorre a múltiplas (pelo menos duas) teorias e/ou hipóteses para interpretar um mesmo conjun- 


\section{ALPERSTEDT \& SIMONE GHISI FEUERSCHÜTTE}

to de dados ou fenômeno, frequentemente, tomando emprestado modelos teóricos de outras disciplinas para explicar a realidade (FLICK, 2009a; ZAPELLINI, FEUERSCHÜTTE, 2015).

Por fim, na triangulação metodológica, Denzin (1978) indica a possibilidade do uso de duas estratégias diferentes: a triangulação dentro de métodos (ou intramétodo) e a entre métodos, em que se usam escalas diferentes ou formas distintas de obter dados, no primeiro caso; e a combinação de formas de coleta distintas no segundo (FLICK, 2009a).

Flick (1992; 2009a) corrobora a classificação de Denzin (1978) e propõe outras abordagens em triangulação, a saber: triangulação etnográfica reflexiva e triangulação combinada entre abordagens quantitativas e qualitativas, além da triangulação sistemática de perspectivas.

Em síntese, a triangulação pode ser aplicada como uma abordagem para fundamentar ainda mais o conhecimento obtido por meio dos métodos qualitativos e não deve ser compreendida simplesmente como uma ferramenta ou uma estratégia de validação, mas uma alternativa para validação que amplia o espaço, a profundidade e a coerência nas condutas metodológicas (FLICK, 2009b, p. 362).

Três implicações são possíveis com base no emprego de triangulação em pesquisa, de acordo com Flick (2013):

a. Convergência de resultados: os resultados das pesquisas qualitativa e quantitativa (ou os diferentes métodos empregados) confirmam parcial ou totalmente uns aos outros.

b. Complementação: os resultados se concentram em diferentes aspectos da questão de pesquisa e, por serem complementares, permitem visualizar um quadro mais amplo da realidade investigada.

c. Divergência ou contradição: os dados obtidos por uma metodologia de pesquisa podem ser distintos daqueles coletados com a outra, exigindo um novo estudo que esclareça teórica ou empiricamente a divergência e dê conta das razões e motivações por trás dela. 
Para Azevedo et al. (2013, p. 4), o uso de múltiplos métodos pode ajudar a descobrir dimensões desviantes do fenômeno, o que significa que diferentes pontos de vista podem produzir alguns elementos que não se ajustam à determinada teoria ou modelo. Dessa forma, velhas teorias são modificadas ou novas teorias podem ser desenvolvidas, além de uma possível síntese ou integração de teorias.

Como evidenciado até aqui, diferentemente do que possa parecer numa análise preliminar, o procedimento de triangulação não se constitui em mero instrumento de confirmação de evidências ou visões acerca de um fenômeno em estudo. Para além dessa possibilidade, assume-se a triangulação como procedimento que acolhe a ocorrência de contradições entre olhares distintos que deverão, portanto, ser aprofundados em novas investigações. 


\section{PROCEDIMENTOS METODOLÓGICOS}

O presente artigo focaliza a investigação acerca do uso do procedimento de triangulação em teses e dissertações no campo da administração no Brasil. Os procedimentos metodológicos utilizados para alcançar esse objetivo foram guiados pela estratégia da pesquisa documental, realizada com base no banco de teses e dissertações da Capes (http:/ / bancodeteses.capes.gov. br). Ainda que não tenha sido utilizado filtro temporal na busca realizada, na ocasião, o sítio eletrônico consultado trouxe à tona apenas trabalhos defendidos nos anos de 2011 e 2012.

$\mathrm{Na}$ busca avançada na referida base de dados, utilizou-se como descritores a palavra "Administração", para área do conhecimento, e a palavra "triangulação", indexada no título, no resumo ou nas palavras-chave dos respectivos trabalhos. A pesquisa inicial retornou com 76 ocorrências, sendo composta por 49 dissertações de mestrado acadêmico, 13 dissertações de mestrado profissional e 14 teses de doutorado. De posse dos respectivos títulos, foi realizada uma busca dos textos completos dos trabalhos disponibilizados na internet (que não eram disponibilizados no site inicialmente consultado), localizando-se um total de 66 trabalhos, que foram analisados com base na leitura das seções de resumo, introdução e metodologia.

A análise dos trabalhos foi orientada por duas fases distintas, aqui denominadas de: (1) etapa diagnóstica e (2) etapa analítica. A primeira etapa identificou o(s) tipo(s) de técnica(s) de coleta de dados ou fonte(s) de evidência utilizado(s); e a segunda etapa se concentrou na escolha intencional de alguns trabalhos, de modo a analisar e utilizar como exemplo a adoção do procedimento de triangulação sob diferentes enfoques metodológicos. A seleção priorizou a escolha de trabalhos por tipo de triangulação utilizada, para além de fornecer uma breve descrição dos seus resultados, realizar a descrição de como o procedimento foi operacionalizado, de forma a investigar os condicionantes metodológicos e os desdobramentos ocorridos sobre os resultados.

Com base nos objetivos deste artigo, julgou-se oportuno e elucidativo que a presente pesquisa se utilizasse igualmente da estratégia de trian- 
gulação para análise dos seus próprios dados. Nesse sentido, enquanto o procedimento de coleta envolveu exclusivamente a pesquisa documental, como mencionado, a análise dos dados ocorreu baseada na triangulação de pesquisadores.

Dessa forma, individualmente, cada um dos pesquisadores envolvidos nesta etapa analisou a totalidade de teses e dissertações, diagnosticando as metodologias utilizadas e o tipo de triangulação empregada (nem todos os trabalhos explicitam a tipologia de triangulação utilizada). Em seguida, os achados individuais dos pesquisadores foram confrontados, buscando-se identificar contradições ou omissões de alguma parte. Só então o texto de apresentação dos resultados foi construído. 


\section{ALPERSTEDT \& SIMONE GHISI FEUERSCHÜTTE}

\section{APRESENTAÇÃO E DISCUSSÃO DOS RESULTADOS}

A observação inicial das teses e dissertações demonstrou a existência de uma diversidade de temas ligados à área da administração, em cujas pesquisas a triangulação foi empregada. Igualmente, foram identificados os diferentes procedimentos metodológicos empregados na elaboração dos trabalhos analisados. Julgou-se adequado esse procedimento inicial a fim de identificar os tipos de triangulação empregados nos estudos, para posterior escolha dos trabalhos que serviriam de exemplos de triangulação. Observou-se, então, uma predominância da utilização de entrevistas como procedimento/técnica principal de coleta de dados. Na verdade, identificou-se que - com exceção do estudo de Dias (2011), que empregou uso do grupo focal $^{1}$-, todas as teses e dissertações analisadas utilizaram entrevista como procedimento de coleta de dados. Além da entrevista, a observação (participante e não participante), a análise de documentos e os questionários foram identificados como as mais recorrentes metodologias utilizadas nas pesquisas analisadas, conforme pode ser observado no Quadro 3.

Quadro 3 Abordagens e técnicas utilizadas nos trabalhos analisados

\begin{tabular}{|c|c|c|c|c|c|c|c|}
\hline \multirow{2}{*}{\multicolumn{2}{|c|}{ AUTORES }} & \multicolumn{2}{|c|}{ ANO } & \multirow{2}{*}{$\begin{array}{c}\text { TIPO } \\
\text { TRABA- } \\
\text { LHO }\end{array}$} & \multirow{2}{*}{$\begin{array}{c}\text { ABORDAGEM } \\
\text { METODO- } \\
\text { LÓGICA }\end{array}$} & \multicolumn{2}{|c|}{$\begin{array}{c}\text { TÉCNICA } \\
\text { UTILIZADA }\end{array}$} \\
\hline & & & 12 & & & 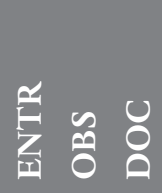 & 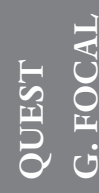 \\
\hline 1 & NEVES & $\mathrm{x}$ & & Dissertação & Qualitativo & $\mathrm{X} X \mathrm{X}$ & \\
\hline 2 & REIS & $\mathrm{x}$ & & Dissertação & Quali/Quanti & $\mathrm{X}$ & $\mathrm{X}$ \\
\hline 3 & FERNANDES & & $\mathrm{x}$ & Dissertação & Quali/Quanti & $\mathrm{X}$ & $\mathrm{X}$ \\
\hline
\end{tabular}

1 Segundo Oliveira e de Freitas (1998), os grupos focais podem ser entendidos como um tipo de entrevista em profundidade realizada com um grupo de pessoas, normalmente pequeno, ao mesmo tempo. A opção metodológica justifica-se na intenção do pesquisador analisar mais o processo de interação dos envolvidos (o grupo) perante determinado tema do que o simples somatório de respostas individuais dos sujeitos. A justificativa do autor (DIAS, 2011) para a utilização de grupo focal, em vez de entrevistas individuais, é justamente essa - foco no grupo e não no sujeito individualmente. 


\begin{tabular}{|c|c|c|c|c|c|c|c|c|c|}
\hline 4 & FLECK & & $\mathrm{x}$ & Tese & Quali/Quanti & $\mathrm{X}$ & & $\mathrm{X}$ & \\
\hline 5 & BORGES & & $\mathrm{x}$ & Tese & Qualitativo & $\mathrm{X}$ & & $\mathrm{X}$ & \\
\hline 6 & BOAVENTURA & $\mathrm{x}$ & & Dissertação & Qualitativo & $\mathrm{X}$ & $\mathrm{X}$ & $\mathrm{X}$ & \\
\hline 7 & PONTE & $\mathrm{x}$ & & Dissertação & Qualitativo & $\mathrm{X}$ & $\mathrm{X}$ & $\mathrm{X}$ & \\
\hline 8 & SILVA & $\mathrm{x}$ & & Dissertação & Quali/Quanti & $\mathrm{X}$ & & $\mathrm{X}$ & $\mathrm{X}$ \\
\hline 9 & CUNHA & $\mathrm{x}$ & & Dissertação & Qualitativo & $\mathrm{X}$ & & & $\mathrm{X}$ \\
\hline 10 & SARPA & $\mathrm{x}$ & & Dissertação & Qualitativo & $\mathrm{X}$ & $\mathrm{X}$ & $\mathrm{X}$ & \\
\hline 11 & LEITE & $\mathrm{x}$ & & Dissertação & Quali/Quanti & $\mathrm{X}$ & & & $\mathrm{X}$ \\
\hline 12 & CARVALHO & $\mathrm{x}$ & & Dissertação & Qualitativo & $\mathrm{X}$ & $\mathrm{X}$ & $\mathrm{X}$ & \\
\hline 13 & DIAS & $\mathrm{x}$ & & Tese & Quali/Quanti & & & $\mathrm{X}$ & $\mathrm{X}$ \\
\hline 14 & PIRES & $\mathrm{x}$ & & Tese & Quali/Quanti & $\mathrm{X}$ & & & $\mathrm{X}$ \\
\hline 15 & BARROS & $\mathrm{x}$ & & Dissertação & Qualitativo & $\mathrm{X}$ & & $\mathrm{X}$ & \\
\hline 16 & BORLIDO & $\mathrm{x}$ & & Dissertação & Quali/Quanti & $\mathrm{X}$ & & $\mathrm{X}$ & $\mathrm{X}$ \\
\hline 17 & ANDRADE & $\mathrm{x}$ & & Dissertação & Quali/Quanti & $\mathrm{X}$ & & & $\mathrm{X}$ \\
\hline 18 & BRITO & $\mathrm{x}$ & & Dissertação & Qualitativo & $\mathrm{X}$ & & $\mathrm{X}$ & \\
\hline 19 & CAGGY & $\mathrm{x}$ & & Dissertação & Quali/Quanti & $\mathrm{X}$ & & $\mathrm{X}$ & $\mathrm{X}$ \\
\hline 20 & GOULART & $\mathrm{x}$ & & Tese & Qualitativo & $\mathrm{X}$ & $\mathrm{X}$ & $\mathrm{X}$ & \\
\hline 21 & MIGOWSKI & $\mathrm{X}$ & & Dissertação & Quali/Quanti & $\mathrm{X}$ & $\mathrm{X}$ & & $\mathrm{X}$ \\
\hline 22 & ALVAREZ & $\mathrm{x}$ & & Dissertação & Quali/Quanti & $\mathrm{X}$ & & & $\mathrm{X}$ \\
\hline 23 & CAVALCANTI & $\mathrm{x}$ & & Dissertação & Qualitativo & $\mathrm{X}$ & & & \\
\hline 24 & MORAIS & $\mathrm{x}$ & & Dissertação & Quali/Quanti & $\mathrm{X}$ & & & $\mathrm{X}$ \\
\hline 25 & BONVICINI & $\mathrm{x}$ & & Dissertação & Qualitativo & $\mathrm{X}$ & & & \\
\hline 26 & PASINI & $\mathrm{x}$ & & Dissertação & Quali/Quanti & $\mathrm{X}$ & & $\mathrm{X}$ & \\
\hline 27 & LAND & $\mathrm{x}$ & & Dissertação & Quali/Quanti & $\mathrm{X}$ & $\mathrm{X}$ & $\mathrm{X}$ & $\mathrm{X}$ \\
\hline 28 & ARAUJO & $\mathrm{x}$ & & Dissertação & Quali/Quanti & $\mathrm{X}$ & & & $\mathrm{X}$ \\
\hline 29 & VACONCELOS & $\mathrm{x}$ & & Dissertação & Qualitativo & $\mathrm{X}$ & $\mathrm{X}$ & $\mathrm{X}$ & \\
\hline 30 & LINS & & $\mathrm{X}$ & Dissertação & Qualitativo & $\mathrm{X}$ & $\mathrm{X}$ & & $\mathrm{X} X$ \\
\hline 31 & GASPAR & & $\mathrm{X}$ & Dissertação & Qualitativo & $\mathrm{X}$ & $\mathrm{X}$ & $\mathrm{X}$ & \\
\hline 32 & FARIA & & $\mathrm{X}$ & Dissertação & Qualitativo & $\mathrm{X}$ & $\mathrm{X}$ & $\mathrm{X}$ & \\
\hline 33 & MAZZA & & $\mathrm{X}$ & Dissertação & Qualitativo & $\mathrm{X}$ & $\mathrm{X}$ & $\mathrm{X}$ & \\
\hline 34 & LUCHESI & & $\mathrm{X}$ & Dissertação & Qualitativo & $\mathrm{X}$ & $\mathrm{X}$ & & \\
\hline 35 & HENRIQUES & & $\mathrm{X}$ & Dissertação & Qualitativo & $\mathrm{X}$ & & $\mathrm{X}$ & \\
\hline 36 & MATOS & & $\mathrm{X}$ & Dissertação & Quali/Quanti & $\mathrm{X}$ & & & $\mathrm{X}$ \\
\hline 37 & OLIVEIRA & & $\mathrm{X}$ & Dissertação & Qualitativo & $\mathrm{X}$ & $\mathrm{X}$ & & \\
\hline
\end{tabular}




\begin{tabular}{|c|c|c|c|c|c|c|c|c|}
\hline 38 & WEBER & $\mathrm{X}$ & Dissertação & Qualitativo & $\mathrm{X}$ & & $\mathrm{X}$ & \\
\hline 39 & $\begin{array}{l}\text { MAGALHÃES } \\
\text { FILHO }\end{array}$ & $\mathrm{X}$ & Tese & Qualitativo & $\mathrm{X}$ & $\mathrm{X}$ & $\mathrm{X}$ & $\mathrm{x}$ \\
\hline 40 & SILVA & $\mathrm{x}$ & Dissertação & Qualitativo & $\mathrm{x}$ & & $\mathrm{X}$ & \\
\hline 41 & $\begin{array}{l}\text { GLÓRIA JU- } \\
\text { NIOR }\end{array}$ & $\mathrm{X}$ & Dissertação & Qualitativo & $\mathrm{X}$ & $\mathrm{X}$ & $\mathrm{X}$ & $\mathrm{x}$ \\
\hline 42 & AYRES & $\mathrm{X}$ & Dissertação & Quali/Quanti & $\mathrm{X}$ & & $\mathrm{X}$ & $\mathrm{X} \quad \mathrm{X}$ \\
\hline 43 & AZEVEDO & $\mathrm{X}$ & Dissertação & Quali/Quanti & $\mathrm{X}$ & $\mathrm{X}$ & $\mathrm{X}$ & \\
\hline 44 & NICOLAI & $\mathrm{X}$ & Dissertação & Qualitativo & $\mathrm{X}$ & & $\mathrm{X}$ & \\
\hline 45 & SILVA & $\mathrm{X}$ & Tese & Qualitativo & $\mathrm{X}$ & & $\mathrm{X}$ & $\mathrm{X}$ \\
\hline 46 & SILVA & $\mathrm{X}$ & Dissertação & Quali/Quanti & $\mathrm{X}$ & & & $\mathrm{X}$ \\
\hline 47 & OLIVEIRA & $\mathrm{X}$ & Dissertação & Qualitativo & $\mathrm{x}$ & & & \\
\hline 48 & COSTA & $\mathrm{X}$ & Tese & Qualitativo & $\mathrm{X}$ & & $\mathrm{X}$ & \\
\hline 49 & JARDEWESKI & $\mathrm{X}$ & Dissertação & Qualitativo & $\mathrm{X}$ & & & \\
\hline 50 & FERREIRA & $\mathrm{X}$ & Dissertação & Qualitativo & $\mathrm{X}$ & $\mathrm{X}$ & & \\
\hline 51 & MULLER & $\mathrm{X}$ & Dissertação & Qualitativo & $\mathrm{X}$ & & $\mathrm{X}$ & \\
\hline 52 & ALVES & $\mathrm{X}$ & Dissertação & Quali/Quanti & $\mathrm{X}$ & & & $\mathrm{x}$ \\
\hline 53 & AZEVEDO & $\mathrm{X}$ & Tese & Qualitativo & $\mathrm{X}$ & & $\mathrm{X}$ & \\
\hline 54 & COUTO & $\mathrm{X}$ & Dissertação & Quali/Quanti & $\mathrm{X}$ & $\mathrm{X}$ & $\mathrm{X}$ & $\mathrm{X}$ \\
\hline 55 & BEDRAN & $\mathrm{X}$ & Dissertação & Quali/Quanti & $\mathrm{X}$ & & & $\mathrm{x}$ \\
\hline 56 & DANNA & $\mathrm{X}$ & Dissertação & Qualitativo & $\mathrm{X}$ & & $\mathrm{X}$ & \\
\hline 57 & ALBUQUERQUE & $\mathrm{X}$ & Dissertação & Qualitativo & $\mathrm{X}$ & & $\mathrm{X}$ & \\
\hline 58 & MARIUTTI & $\mathrm{X}$ & Dissertação & Qualitativo & $\mathrm{X}$ & & & \\
\hline 59 & FEITOSA & $\mathrm{X}$ & Dissertação & Quali/Quanti & $\mathrm{X}$ & $\mathrm{X}$ & $\mathrm{x}$ & \\
\hline 60 & SANTOS & $\mathrm{X}$ & Dissertação & Qualitativo & $\mathrm{X}$ & $\mathrm{X}$ & $\mathrm{x}$ & \\
\hline 61 & TOLEDO & $\mathrm{X}$ & Dissertação & Quali/Quanti & $\mathrm{X}$ & $\mathrm{X}$ & & $\mathrm{X}$ \\
\hline 62 & FISCHER & $\mathrm{X}$ & Tese & Qualitativo & $\mathrm{X}$ & $\mathrm{X}$ & $\mathrm{X}$ & $\mathrm{X}$ \\
\hline 63 & BIRRER & $\mathrm{X}$ & Dissertação & Quali/Quanti & $\mathrm{X}$ & & & $\mathrm{X}$ \\
\hline 64 & $\begin{array}{l}\text { VELOSO E } \\
\text { SOUZA }\end{array}$ & $\mathrm{X}$ & Tese & Quali/Quanti & $\mathrm{X}$ & & & $\mathrm{X} \quad \mathrm{X}$ \\
\hline 65 & BEYDA & $\mathrm{X}$ & Tese & Qualitativo & $\mathrm{X}$ & & $\mathrm{X}$ & \\
\hline 66 & BASTOS & $\mathrm{x}$ & Tese & Quali/Quanti & $\mathrm{X}$ & $\mathrm{X}$ & & \\
\hline
\end{tabular}

Fonte: Elaborado pelos autores. 
Em se tratando da utilização da triangulação, os trabalhos analisados exploraram de formas diferentes as possibilidades que o procedimento admite, tendo sido identificadas todas as tipologias mencionadas por Denzin (1978), quais sejam: triangulação de dados, de investigadores, de teorias e metodológica (dentro de método e entre métodos).

A triangulação metodológica entre métodos foi a tipologia de triangulação mais observada nos estudos analisados. Possivelmente, essa constatação ocorre em virtude do entendimento geral da triangulação ser, com frequência, ligada à utilização de mais de um método na análise de um determinado fenômeno. Sob essa perspectiva, sabe-se que o conceito tradicional de triangulação envolvia tal entendimento. Para exemplificar a utilização dessa tipologia de triangulação é apresentado o estudo de Ponte (2011).

A dissertação da autora teve como objetivo descrever a influência da cultura organizacional sobre os relacionamentos amorosos entre os executivos médios de uma empresa de alimentos. Para a coleta de dados, a autora utilizou-se de entrevistas com roteiro semiestruturado com participantes da organização, combinadas à consulta de documentos e à observação. Essa última técnica foi justificada pela autora por conta de seu vínculo como colaboradora da empresa, o que, segundo ela, permitiu observar, ao longo dos dez anos de contrato com a organização, o expressivo número de envolvimentos amorosos entre funcionários, bem como a ocorrência de vários casos de divórcio de seus executivos.

Os dados provenientes das entrevistas realizadas no estudo de Pontes (2011), com dez respondentes da organização, foram analisados segundo a técnica de análise de conteúdo. Em sequência, com base em uma proposta de Estudo de Caso, a autora apresentou dados documentais da organização e procurou combiná-los às observações conduzidas no campo, assim, buscando uma convergência e confirmação dos argumentos com os dados gerados da aplicação dos dois métodos utilizados.

O estudo de Ponte (2011) evidencia que não há clareza de como ocorre a triangulação metodológica na prática, visto que a autora não mostra como as fontes de evidência coletadas estão submetidas a um procedimento de triangulação que, efetivamente, promove a combinação de métodos 


\section{ALPERSTEDT \& SIMONE GHISI FEUERSCHÜTTE}

distintos acerca de um mesmo objeto. Além disso, constatou-se a omissão do termo triangulação no trabalho, tendo sido citado somente no resumo do estudo. A análise da discussão dos resultados e das conclusões do estudo demonstra, portanto, que não há um esclarecimento sobre como convergem, se complementam ou mesmo divergem os dados e as evidências analisados com base nos distintos métodos utilizados no procedimento de triangulação.

Outra forma de triangulação observada foi a triangulação - metodológica - dentro de método ou intramétodo. Nesse sentido, como visto anteriormente, uma pesquisa pode utilizar diferentes subescalas em um questionário ou diferentes formas para investigar uma mesma questão (mas dentro de um mesmo método). Sob esse entendimento foram identificados os estudos de Barros (2011) e Alves (2012) como exemplos da utilização desse tipo de triangulação.

Na dissertação de Alves (2012), o autor objetivou analisar o sentido do trabalho para funcionários do setor de comunicação de uma instituição pública mineira - a EMATER-MG. Para alcançar tal objetivo, o autor realizou entrevistas e questionários com os funcionários do setor. A utilização de entrevistas e questionários, por si só, poderia caracterizar novamente o procedimento de triangulação entre métodos, considerando que o autor destaca a utilização dessa tipologia de triangulação. Mas, com a análise dos instrumentos de coleta de dados utilizados no estudo - principalmente o questionário -, pode-se considerar a pesquisa como um exemplo de utilização de triangulação dentro de método.

Nesse sentido, o que se destaca é que o questionário utilizado na dissertação de Alves (2012) apresenta diferentes formas de investigar a questão do sentido do trabalho para os sujeitos investigados. Além da utilização de escalas quantitativas para avaliação do sentido do trabalho para os investigados, o questionário empreende a aplicação da técnica de associação livre de palavras e, ao final, ainda investe em perguntas abertas sobre o fenômeno pesquisado - sentido do trabalho - triangulando, dentro de um mesmo método (neste caso, o questionário), três diferentes formas de abordar a questão. 
Apesar da efetiva utilização do procedimento de triangulação, o texto de Alves (2012) não apresenta destaque acerca de como as informações foram obtidas - com base em distintos métodos, ou mesmo dentro do método do questionário - e se apresentam complementaridade ou divergências. Ao longo da discussão dos resultados e das considerações finais do estudo, é perceptível o esforço de análise e síntese da autora, mas há pouco esclarecimento de como se deu efetivamente a triangulação proposta.

De forma alternativa, a triangulação intramétodo também pôde ser identificada na pesquisa de mestrado de Barros (2011), a qual teve como objetivo analisar competências profissionais de médicos de um hospital privado.

Como procedimento de coleta de dados, o autor realizou entrevistas com 21 médicos do hospital investigado e, durante as entrevistas - ou mais precisamente ao final delas -, o pesquisador utilizou-se de uma técnica projetiva de associação de figuras, com o intuito de registrar percepções e concepções que não teriam sido verbalizadas na parte formal da entrevista. Esse procedimento consistia em solicitar aos sujeitos investigados que comentassem cada uma das imagens apresentadas com base na atuação profissional realizada naquele hospital, ou seja, tinha a intenção de, dentro do próprio método de entrevista, abordar, sob diferentes formas, a mesma questão-problema - triangulação intramétodo.

O estudo em questão reforçou o entendimento acerca do tipo de triangulação adotado ao afirmar que "[...] dentro da abordagem qualitativa, as entrevistas e a técnica projetiva de associação se complementaram com vistas a aprofundar na compreensão do fenômeno em questão, visando $\grave{a}$ maior confiabilidade e qualidade nas análises" (ALVES, 2012, p.45-46, grifo nosso). Tal complementariedade experimentada dentro de um mesmo método ficou evidente nessa pesquisa, sendo um dos principais recursos utilizados pelo pesquisador na busca da confirmação e confiabilidade das informações prestadas pelos sujeitos do estudo, além de abrir espaço para o surgimento de percepções distintas de entendimento com base no estímulo visual adotado.

Entre as formas mais tradicionais de triangulação utilizadas em pesquisa qualitativa encontra-se, também, a triangulação de dados - ou de 


\section{ALPERSTEDT \& SIMONE GHISI FEUERSCHÜTTE}

fonte de dados - que, conforme Denzin (1978), pode ser entendida quando o pesquisador utiliza diferentes fontes de dados, sem se valer de métodos distintos. Nesse sentido, a dissertação de Borlido (2011) se propôs a descrever e analisar como se encontram configurados os valores organizacionais e do trabalho de jovens recém-inseridos no mercado de trabalho, por meio do programa do Espro (Associação de Ensino Social Profissionalizante), em Belo Horizonte (MG).

Para tanto, a autora realizou uma análise por meio de documentos, questionários e entrevistas semiestruturadas. Conquanto trate-se novamente de uma abordagem de triangulação de métodos, o estudo também se caracteriza como triangulação de dados, pois a pesquisadora realizou entrevistas com diferentes grupos de respondentes - colaboradores do Espro e com jovens alunos da instituição.

Os dados provenientes das entrevistas foram submetidos à análise de conteúdo e, na discussão dos resultados, Borlido (2011) faz uma breve convergência entre as entrevistas dos três colaboradores em relação às respostas dos 16 jovens convidados para o estudo.

O que se percebe nesse trabalho é que, embora tenha-se valido de múltiplos métodos e fontes de evidência, a discussão acerca da validação, confirmação ou mesmo as contradições entre as fontes distintas não são apontadas pela autora de forma aprofundada, o que acaba ficando como conclusão intrínseca ao leitor.

Além das formas de triangulação mais usualmente utilizadas em pesquisa da área da Administração - quais sejam: triangulação metodológica e de dados (AZEVEDO et al., 2013; ZAPELLINI; FEUERSCHÜTTE, 2015), conforme apontado, o entendimento mais atual e mais amplo sobre triangulação possibilita o emprego de formas alternativas de utilização do procedimento. Desse modo, além dos tipos já apresentados, observou-se, nos estudos analisados, o emprego das tipologias de triangulação de pesquisadores e triangulação de teorias.

A triangulação de pesquisadores foi identificada no trabalho de Danna (2012), que investigou a capacidade organizacional para mudança na Câmara Federal dos Deputados. Em sua pesquisa, a autora realizou entre- 
vistas com sujeitos diretamente ligados ao processo de mudança organizacional na instituição legislativa, além de pesquisa em diversos documentos institucionais (como planos estratégicos corporativos e setoriais, relatórios de gestão estratégica, indicadores da organização, normativos vinculados à gestão estratégica da organização, estudos, atas de reuniões, reportagens de revistas e boletins internos, etc.).

Tal diversidade de fontes documentais já poderia ser entendida como uma triangulação de dados. Contudo a principal contribuição da pesquisa da autora - sobre o tema da triangulação - é em relação ao seu processo de análise dos dados das entrevistas, que é claramente caracterizado como uma triangulação de pesquisadores.

Para a realização desse procedimento, a autora iniciou a análise de conteúdo agrupando trechos das falas dos sujeitos entrevistados que possuíam elementos comuns e que dariam origem às categorias de facilitadores e dificultadores à mudança na organização investigada. Em seguida, esses agrupamentos das verbalizações identificados foram encaminhados - sem a nomenclatura inicialmente dada pela pesquisadora - a quatro outros pesquisadores (um doutor e três mestrandos em Administração, integrantes de um grupo de pesquisa sobre Criatividade e Inovação nas Organizações), para que realizassem análise individual dos dados coletados.

Com tal procedimento, Danna (2012) relata que cada pesquisador deveria nomear livremente as categorias previamente identificadas pela pesquisadora, tendo, ainda, a liberdade de separar ou agrupar verbalizações, criar ou excluir categorias - e assim o fizeram. Durante o processo de triangulação, verificou-se convergência em grande parte das categorias inicialmente identificadas pela pesquisadora. Não obstante, duas categorias apresentaram divergências e tiveram alterações, com base nas considerações dos outros pesquisadores. Uma das categorias, por intervenção dos pesquisadores auxiliares, foi separada em duas categorias distintas; outra categoria, os pesquisadores nomearam de forma unânime, mas de modo diferente do que a pesquisadora havia inicialmente idealizado. Dessa forma, a triangulação de pesquisadores possibilitou alterações/ contribuições relevantes para o resultado final da pesquisa, sendo o procedimento con- 


\section{ALPERSTEDT \& SIMONE GHISI FEUERSCHÜTTE}

siderado fundamental pela autora para a qualificação da interpretação dos resultados.

Destaca-se, no caso da pesquisa supracitada, que a triangulação de pesquisadores ocorreu durante a fase de análise dos dados. Não obstante tal possibilidade, essa tipologia de triangulação viabiliza a contribuição de diferentes pesquisadores na própria coleta de dados. Dessa forma, diferentes entrevistadores, ou observadores de um fenômeno, podem dirimir o viés potencial que vem de uma única pessoa coletando dados (DENZIN, 1978).

Por fim, a triangulação de teorias é uma tipologia de triangulação que não costuma ser observada ou ao menos declarada nos trabalhos realizados na área da Administração. Nesse sentido, o único trabalho identificado como utilizador de triangulação de teorias foi a tese de Borges (2012), cujo objetivo era o de fazer avançar o conhecimento sobre a carreira empreendedora, com base no estudo das microfundações que a constituem e que a tornam possível, considerando as dimensões privada (individual) e coletiva (pública e estrutural) da carreira de empreendedores que criaram e passaram a gerir os seus próprios negócios.

A tese realizou uma pesquisa qualitativa fundamentada em teorias que se inserem predominantemente no campo da Psicologia Social, da Sociologia e da Mitologia para investigar a carreira empreendedora, explorando a questão: por que e como o empreendedorismo gera o empreendedor?

O estudo pautou-se por uma abordagem interpretativa em primeiro plano, como alternativa ao paradigma funcionalista - que, segundo a autora, é predominante na área - e, em segundo plano, em estudos vinculados ao paradigma estruturalista, pós-estruturalista, pós- moderno e aos estudos críticos em gestão, e é aqui que, segundo ela, está caracterizada a triangulação de teorias e perspectivas.

Para analisar por que e como o empreendedorismo gera o empreendedor, o estudo caminhou por dois campos do conhecimento: a Psicologia e a Sociologia. A pesquisa foi conduzida em duas etapas: na primeira etapa, foi realizada a análise de um texto jornalístico sobre a carreira empreendedora, composto por vinte e uma matérias de jornal, cada uma sobre um empreendedor. A segunda etapa foi conduzida com 18 empreendedores 
que foram contatados e aceitaram participar do estudo. Os dados levantados na primeira etapa foram interpretados por meio da análise de conteúdo (lexical por frequência, lexical por sentido e análise semântica por temas); já nos da segunda etapa, foi aplicado o método da história de vida por meio de entrevista semiestruturada, e a análise deu-se mediante a análise de conteúdo temática.

Embora a autora situe preliminarmente seu estudo na triangulação de teorias e perspectivas, também se propôs a fazer triangulação de dados entre as duas etapas, o que pareceu muito evidente, considerando a combinação entre as fontes de evidência coletadas em momentos, locais e pessoas distintos, e a perspectiva multiparadigmática de conversação reflexiva com perspectivas teóricas múltiplas, que deu um caráter conceitual e crítico ao trabalho. Observa-se que o ineditismo destacado na tese é também o de conduzir, de maneira rigorosa, um método pouco usual nos estudos na área de Administração, motivo pelo qual pode caracterizar-se como uma referência para desenvolvimento de estudos sob essa proposta de triangulação. Não é de se admirar de que se trate de uma tese de doutorado, pois o trabalho rompe com a visão excludente do posicionamento epistemológico comum, tendo em vista a tese da incomensurabilidade dos tão conhecidos paradigmas de Burrell e Morgan (PAES DE PAULA, 2015), o que talvez pudesse ser mais difícil em uma dissertação de mestrado. Nesse sentido, Borges (2012) busca superar a incompletude cognitiva, o que exige um "trabalho de escavação" para encontrar elementos perdidos ou que não foram percebidos, a partir da construção do conhecimento em bases já consolidadas (SERVA, 2015, p. 15). Tal modo de conduzir pesquisas, embora ainda pouco usual na área de Administração, possibilita uma abertura ao campo, na medida em que permite explorar diferentes teorias que a princípio poderiam parecer contrárias ou divergentes entre si, favorecida pelo uso da Triangulação de métodos, dados e teorias. Assim, observa-se um exemplo da possibilidade da análise multiparadigmática e da lógica das matrizes epistêmicas de Paes de Paula (2015).

Com a análise das teses e dissertações investigadas por este estudo algumas considerações acerca do tema triangulação podem ser elaboradas. 


\section{ALPERSTEDT \& SIMONE GHISI FEUERSCHÜTTE}

Nesse sentido, identificou-se, igualmente, às observações de Zapellini e Feuerschütte (2015), a possibilidade de, em uma mesma pesquisa, serem empregados mais de um procedimento de triangulação - por exemplo, dados e métodos -, como assim foi ilustrado em alguns exemplos apresentados neste estudo.

Outro aspecto percebido é que, em determinadas pesquisas, o emprego da triangulação não equilibra de maneira igualitária as metodologias utilizadas, ou seja, os métodos de coleta de dados - ou fonte de dados - não são utilizados com a mesma intensidade para analisar ou interpretar um fenômeno. Em outras palavras, é comum perceber que, certas vezes, os procedimentos de observação (seja participante ou não participante) ou de análise documental são usados como métodos auxiliares para corroborar achados de entrevistas realizadas. Nesses casos, parece existir um método dominante (a entrevista) que produz mais efetivamente os achados da pesquisa e outros métodos (ou fontes de dados) auxiliares - menos contributivos - na construção dos resultados.

Nesse prisma, a pesquisa de Neves (2011), por exemplo - cujo objetivo foi verificar de que forma a violência e o sofrimento se manifestam nas relações de trabalho de profissionais de nível gerencial em uma instituição de ensino -, ilustra essa percepção. O estudo foi realizado com base em oito entrevistas com profissionais de nível gerencial, análise documental e observação não participante realizadas pela autora na organização investigada. Não obstante à utilização das três estratégias de coleta de dados, é visível a imensa predominância da entrevista como contribuinte principal da produção dos resultados do estudo. Os trabalhos analisados permitem afirmar que, em pouquíssimas oportunidades, é possível encontrar resultados da pesquisa advindos das análises documentais ou observações. 


\section{CONSIDERAÇÕES FINAIS}

Ao reportar-se ao objetivo da pesquisa - que pretendeu identificar, analisar e exemplificar o uso da triangulação em teses e dissertações da área da Administração no Brasil - é possível chegar a algumas considerações e conclusões.

A triangulação, como demonstrou este estudo, apresenta-se como um procedimento metodológico que possibilita seu emprego não somente sobre diversas temáticas de pesquisa da área da Administração, mas, além disso, permite ampla gama de possibilidades para seu emprego/utilização.

O procedimento de triangulação entre métodos tem sido a tipologia mais utilizada em pesquisas da área, mas outras formas de triangulação - de dados, de investigadores, de teorias e metodológica dentro de método - e, inclusive, a possibilidade de realizá-las empregando diferentes combinações de procedimentos metodológicos, demonstram a variedade de possibilidades que o procedimento possibilita.

A contribuição do procedimento de triangulação ao rigor científico de um estudo não está necessariamente ligada à corroboração, convergência ou complementação de resultados advindos da aplicação de diferentes metodologias, dados, teorias, abordagens e/ou pesquisadores. A triangulação, enquanto procedimento metodológico, possibilita, igualmente, a divergência ou contradição de achados. Não obstante essa consideração advinda da literatura sobre o tema, destaque pode ser dado à seguinte questão: nas teses e dissertações analisadas no presente artigo, em grande parte das vezes, a triangulação é eleita como um procedimento metodológico que contribui para a obtenção dos resultados da pesquisa; porém nota-se que - tendo utilizada a triangulação para obtenção dos resultados - alguns trabalhos não evidenciam quais foram as divergências ou complementariedades que o uso do procedimento possibilitou em seus resultados.

A triangulação, nesses casos, acaba sendo um termo encontrado quase que exclusivamente na seção de procedimentos metodológicos das pesquisas e pouco lembrada na descrição dos resultados e nas conclusões dos estudos. Mas eventuais divergências, de nenhum modo, devem ser vistas 
como inconvenientes ou preocupantes. Assim, torna-se necessário destacar que o que se busca, em pesquisa qualitativa, é o profundo entendimento dos fenômenos, com suas particularidades, contradições, etc.

Sem embargos das considerações aqui ponderadas, de modo geral, o uso das várias possibilidades de triangulação tem sido visto como um procedimento relacionado ao rigor metodológico e ao incremento da qualidade de pesquisas, incluindo as teses e dissertações aqui analisadas.

Fazer uso da triangulação é dar possibilidade ao pesquisador, à pesquisa realizada e ao conhecimento científico produzido de obterem maior embasamento e sustentação empírica/analítica dos fenômenos investigados. Triangular, enfim, é demonstrar entendimento que dois pontos de vista são melhores do que apenas um.

É certo que esse caminho pode levar ao rompimento de padrões tradicionais de se fazer ciência, na medida em que evidencia diferentes e até contraditórias maneiras de ver o mesmo fenômeno. No entanto poderá contribuir para um entendimento mais profundo e mais complexo do mundo real, pois permite fugir do rótulo dos tradicionais paradigmas que separam os pesquisadores, ao mesmo tempo que pode representar um avanço na pesquisa pela conciliação de interesses cognitivos.

Sugere-se, como agenda para pesquisas futuras, a ampliação das áreas do conhecimento e bases de dados utilizados, visto que o número restrito de pesquisas e o período abrangido podem ser considerados limitações deste estudo. Uma direção estimulada nesse sentido seria a de identificar e analisar trabalhos que explorem a importância do uso da triangulação diante da possibilidade da análise multiparadigmática, considerando a chance de conciliação de interesses cognitivos diversos, combinando e contrapondo teorias, abordagens e paradigmas para descobrir novos caminhos e contribuir para a mitigação da "guerra paradigmática" (PAES de PAULA, 2015; ALPERSTEDT, ANDION, 2017). 


\section{REFERÊNCIAS}

ABDALLA, M.M. et al. Quality in qualitative organizational research: types of triangulation as a methodological alternative. Administração: Ensino e Pesquisa. v.19, n.1, p. 66-98, jan.-abr. 2018.

ALBUQUERQUE, A. E. C. Design-build: uma contribuição para a minimização de problemas entre projeto e construção de obras públicas brasileiras. 2012. 191 f. Dissertação (Mestrado em Administração) - Universidade Federal de Pernambuco, Recife, 2012.

ALPERSTEDT, G. D.; ANDION, C. Por uma pesquisa que faça sentido. Revista de Administração de Empresas, v. 57, n. 6, p. 626-631, 2017.

ALVARES, F. A. C. Cortiços e a segregação no espaço urbano: repercussões na atividade profissional dos indivíduos. 2011. 162f. Dissertação (Mestrado acadêmico em Administração) - Pontifícia Universidade Católica de São Paulo, São Paulo, 2011.

ALVES, G. M. B. Sentido do trabalho e qualidade de vida: um estudo com os profissionais da emater-mg. . 2012. 160 f. Dissertação (Mestrado em Administração) - Faculdade Novos Horizontes, Belo Horizonte, 2012.

ANDRADE, D. L. Valores organizacionais e do trabalho: um estudo com agentes prisionais e agentes socioeducativos em Belo Horizonte. 2011. 128 f. Dissertação (Mestrado em Administração) - Faculdade Novos Horizontes, Belo Horizonte, 2011.

ARAUJO, A. L. Estresse ocupacional e Burnout: um estudo com professores de um curso de graduação em enfermagem de uma Instituição privada em Minas Gerais. 2011. $124 \mathrm{f}$. Dissertação (Mestrado em Administração) - Faculdade Novos Horizontes, Belo Horizonte, 2011.

AZEVEDO, A. L. V. Uso das estatísticas criminais e planejamento das atividades das policiais: um estudo sobre a percepção dos profissionais de segurança pública do Estado do Rio de Janeiro. 2012. 261 f. Tese (Doutorado em Administração) - Fundação Getúlio Vargas/RJ, Rio de Janeiro, 2012.

AZEVEDO, C. E. F. et al. A estratégia de triangulação: objetivos, possibilidades, limitações e proximidades com o pragmatismo. In: ENCONTRO DE ENSINO E PESQUISA EM ADMINISTRAÇÃO E CONTABILIDADE, IV, 2013, Brasília. Anais... Brasília: ANPAD, 2013. p.

AZEVEDO, P. Instrumento de avaliação de projetos de extensão na modalidade de educação a distância. 2012. 223 f. Dissertação (Mestrado em Administração) - Universidade Federal de Santa Catarina, Florianópolis, 2012.

AYRES, S. M. P. M. Proposta de um sistema de capacitação baseada em competências para o Instituto Federal de Educação Ciência e Tecnologia do Sertão Pernambucano. 2012. 176 f. Dissertação (Mestrado em Administração) - Universidade Federal da Paraíba, João Pessoa, 2012.

BARROS, L. E. V. Competências profissionais e sua gestão na área da saúde: um estudo de caso com médicos de um hospital privado mineiro. 2011. 116 f. Dissertação (Mestrado em Administração) - Faculdade Novos Horizontes, Belo Horizonte, 2011. 


\section{ALPERSTEDT \& SIMONE GHISI FEUERSCHÜTTE}

BASTOS, S. A. P. Proposta de um arcabouço analítico na perspectiva relacional para auxílio à gestão de estratégias políticas empresariais: foco no setor elétrico brasileiro. $2012325 \mathrm{f}$. Tese (Doutorado em Administração de Empresas) - Pontifícia Universidade Católica do Rio de Janeiro, Rio de Janeiro, 2012.

BEDRAN, F. N. O cosmopolitanismo como influenciador na formação de imagem de destino: a cidade de São Paulo para estrangeiro. 2012. 157 f. Dissertação (Mestrado em Administração) - Escola Superior de Propaganda e Marketing, São Paulo, 2012.

BEYDA, T. T. Mudanças societárias em empresa familiar: impacto do ipo (initial public offering) na identidade organizacional e identificação. 2012. 232 f. Tese (Doutorado em Administração_ - Pontifícia Universidade Católica do Rio de Janeiro, Rio de Janeiro, 2012.

BIRRER, J. A. Resiliência e aprendizagem: um olhar sobre o comportamento de multiprofissionais da saúde. 2012. 210 f. Dissertação (Mestrado em Administração) - Universidade Federal de Santa Maria, Santa Maria - RS, 2012.

BOAVENTURA, E. F. Implementação do sistema Toyota sob a ótica da gestão de mudanças: uma pesquisa-ação aplicada ao hospital veterinário de Uberaba. 2011. 175 f. Dissertação (Mestrado em Administração) - Universidade Federal de Uberlândia, Uberlândia - MG, 2011.

BORGES, J. F. Quando o empreendedorismo gera o empreendedor: as microfundações da carreira empreendedora. 2012. 293 f. Tese (Doutorado em Administração) - Uuniversidade de São Paulo. São Paulo, 2012.

BORLIDO, F. C. Valores organizacionais e do trabalho na percepção de jovens recém-inseridos no mercado de trabalho: o caso dos alunos do ESPRO. 2011. 147 f. Dissertação (Mestrado em Administração) - Faculdade Novos Horizontes, Belo Horizonte, 2011.

BRITO, J. V. S. O strategizing na visão da média gerência: um estudo de caso na Superintendência do Patrimônio da União na Região Sul do Brasil. 2011. 314 f. Dissertação (Mestrado em Administração) - Universidade do Sul de Santa Catarina, Florianópolis, 2011.

BONVICINI, C. R. Relações de trabalho no agronegócio: percepções de gestores de duas organizações mineiras. 2011. 124 f. Dissertação (Mestrado em Administração) - Faculdade Novos Horizontes, Belo Horizonte, 2011.

CAGGY, R. C. S. S. A interdisciplinaridade revisitada: analisando a prática interdisciplinar em uma Faculdade de Administração da Bahia. 2011. 150 f. Dissertação (Mestrado em Administração) - Universidade Federal da Bahia, Salvador, 2011.

CAMPBELL, D.T.; FISKE, D. W. Convergent and discriminant validation by the multitrait-multimethod matrix. Psychological Bulletin. 56. 1959. pp. 81-105.

CARVALHO, R. N. Cultura organizacional e a questão dos valores na aquisição do banco Real pelo banco Santander. 2011. 123 f. Dissertação (Mestrado Profissional em Administração e Desenvolvimento Empresarial) - Universidade Estácio de Sá, Rio de Janeiro, 2011.

CAVALCANTE, A. C. As iracemas e os príncipes do além-mar: políticas públicas e a exploração do turismo sexual no Ceará. 2011. 291 f. Dissertação (Mestrado em Administração de Empresas) - Universidade de Fortaleza, Fortaleza, 2011. 
COSTA, G. P. Heranças patrimonialistas, (dis)funções burocráticas, práticas gerenciais e os novos arranjos do Estado em rede: entendendo a configuração atual da administração pública brasileira. 2012. 256 f. Tese (Doutorado em Administração) - Fundação Getúlio Vargas/ RJ, Rio de Janeiro, 2012 .

COUTO, W. W. Influência do cargo e grau de instrução na avaliação de sistemas integrados de gestão. 2012. 138 f. Dissertação (Mestrado Profissional em Administração) - Faculdades Integradas de Pedro Leopoldo, Pedro Leopoldo - RS, 2012.

COX, J. W.; HASSARD, E. J. Triangulation in Organizational Research: a Representation. Organization, 12(1), p.109-1133, 2005.

CUNHA, I. C. T. O uso das redes sociais como estratégia de sobrevivência no trabalho. 2011. 95 f. Dissertação (Mestrado Profissional em Administração) - Fundação Getúlio Vargas/ RJ, Rio de Janeiro, 2011.

DANNA, E. C. Capacidade organizacional para mudança: Estudo de caso de uma organização pública legislativa. 2012. 208 f. Dissertação (Mestrado em Administração) - Universidade de Brasília. Brasília - DF, 2012.

DAVIDSON, E. J. Evaluation methodology basics. Thousand Oaks: Sage, 2005.

DENZIN, N. The research act: a theoretical introduction to sociological methods. 2. ed. New York: Mc Graw-Hill, 1978.

DENZIN, N. K.; LINCOLN, Y. S. Introduction: The discipline and practice of qualitative research. In: (Eds.). The Sage Handbook of qualitative research. 4. ed. Thousand Oaks: Sage, 2005. p. 1-32.

DIAS, T. F. Gestão social em empreendimentos econômicos solidários: uma abordagem no Oeste potiguar. 2011. 229 f. Tese (Doutorado em Administração) - Universidade Federal do Rio Grande do Norte, Natal, 2011.

FARIA, P. P. A mudança cultural no processo de aquisição de uma empresa familiar brasileira por um fundo de investimento de private equity estrangeiro. 2012. $103 \mathrm{f}$. Dissertação (Mestrado Profissional em Administração e Desenvolvimento Empresarial) - Universidade Estácio de Sá, Rio de Janeiro, 2012.

FEITOSA, M. J. S. Pegada ecológica do turismo: adaptação e aplicação em Fernando de Noronha-PE. 2012. 201 f. Dissertação (Mestrado em Administração) - Universidade Federal de Pernambuco, Recife, 2012.

FERNANDES, A. C. B. C. Competências gerenciais de enfermeiros de uma instituição hospitalar de Belo Horizonte. 2012. 162 f. Dissertação (Mestrado em Administração) - Faculdade Novos Horizontes, Belo Horizonte, 2012.

FERREIRA, J. H. M. Dimensões de inovação organizacionais e sociais no processo de certificação fair trade: o caso da casa APIS. 2012. 104 f. Dissertação (Mestrado em Administração e Controladoria) - Universidade Federal do Ceará, 2012.

FISCHER, S. D. Implementação da política descentralizada de ensino fundamental: um estudo sobre a gestão escolar em municípios do Estado de Santa Catarina. 2012. 


\section{ALPERSTEDT \& SIMONE GHISI FEUERSCHÜTTE}

279 f. Tese (Doutorado em Administração) - Universidade Federal da Bahia, Salvador, 2012.

FLICK, U. Triangulation revisited: strategy of validation or alternative? Journal for the Theory of Social Behavior, v. 22, n. 2, p. 175-197, 1992.

Qualidade na pesquisa qualitativa. Porto Alegre: Bookman; Artmed, 2009a. . Introdução à pesquisa qualitativa. 3.ed. Porto Alegre: Bookman, 2009b. . Introdução à metodologia de pesquisa. Porto Alegre: Penso, 2013.

FLECK, C. F. A universidade no desenvolvimento do mercado de trabalho: um estudo de caso em Santana do Livramento. 2012. 188 f. Tese (Doutorado em Administração) - Universidade Federal do Rio Grande do Sul, Porto Alegre, 2012.

GASPAR, C. P. Dificuldades de integração e barreiras culturais em aquisições de pequenas e médias empresas por uma empresa de grande porte: um estudo de caso. 2012. 117 f. Dissertação (Mestrado Profissional em Administração e Desenvolvimento Empresarial) - Universidade Estácio de Sá, Rio de Janeiro, 2012.

GLORIA JUNIOR, O. S. Competências e habilidades relevantes para um chefe de unidade descentralizada de perícia da polícia federal. 2012. 186 f. Dissertação (Mestrado em Administração) - Fundação Getúlio Vargas/RJ, Rio de Janeiro, 2012.

GOULART, M. S. B. Participação e accountability no controle do orçamento público: o caso do Conselho de Desenvolvimento Regional de Itajaí. 2011. 226 f. Tese (Doutorado em Administração) - Universidade Federal da Bahia, Salvador, 2011.

HENRIQUES, A. C. V. Transferência de conhecimento organizacional entre países: um estudo de caso acerca dos dificultadores desse processo com ênfase na atuação de recursos humanos. 2012. 140 f. Dissertação (Mestrado em Administração) - Universidade Federal do Rio Grande do Sul - RS, Porto Alegre, 2012.

JARDEWESKI, C. J. F. O expatriado e a transferência de conhecimento: um estudo de caso na filial brasileira de um banco estrangeiro. 2012. 180 f. Dissertação (Mestrado em Administração) - Universidade Federal do Paraná, Curitiba2012.

KUMAR, K. Da sociedade pós-industrial à pós-modernas: novas teorias sobre o mundo contemporâneo. Rio de Janeiro: Jorge Zahar, 1997.

LAND, A. G. Modelo de adaptação evolucionária da vantagem da complexidade: um estudo de caso em uma Escola técnica de saúde de João Pessoa 2011. 148 f. Dissertação (Mestrado em Administração) - Universidade Federal da Paraíba, João Pessoa, 2011.

LEITE, N. E. Justiça no trabalho e atitudes retaliatórias: estudo com docentes do Campus II do CEFET-MG. 2011. 113 f. Dissertação (Mestrado em Administração) - Faculdade Novos Horizontes, Belo Horizonte, 2011.

LINS, A. M. Educação fiscal: a experiência do Grupo de Educação Fiscal Estadual de Pernambuco. 2012142 f. Dissertação (Mestrado em Administração) - Fundação Getúlio Vargas/RJ, Rio de Janeiro, 2012. 
LUCHESI, J. R. S. A emoção no contexto da prestação de serviços: um estudo aplicado junto a usuárias dos serviços de obstetrícia de um hospital público. 2012. 109 f. Dissertação (Mestrado em Administração) - Universidade de Caxias do Sul - RS, 2012.

MAGALHAES FILHO, L. L. Efeitos do conhecimento sobre a apropriação de renda na saúde suplementar: o caso UNIMED de São José dos Campos. 2012. 165 f. Tese (Doutorado em Administração de Empresas) - Fundação Getúlio Vargas/SP, São Paulo, 2012.

MARIUTTI, F. G. Identidade de marca-pais: comunicação da marca Brasil nos Estados Unidos da América. 2012. 232 f. Dissertação (Mestrado em Administração de Organizações) Universidade de São Paulo, Ribeirão Preto - SP, 2012.

MATOS, L. A. Estágio de vantagem competitiva: estudo de caso da incorporadora penta. 2012. 133 f. Dissertação (Mestrado em Administração de Empresas) - Universidade de Fortaleza - CE, Fortaleza, 2012.

MAZZA, S. As competências dos gerentes de melhor desempenho em um banco de varejo estatal. 2012. 110 f. Dissertação (Mestrado Profissional em Administração e Desenvolvimento Empresarial) - Universidade Estácio de Sá, Rio de Janeiro, 2012.

MIGOWSKI, S.A. Capacitação de funcionários assistenciais ingressantes - recurso estratégico para a manutenção da qualidade em ambiente hospitalar de alta rotatividade. 2011. $167 \mathrm{f}$. Dissertação (Mestrado em Administração) - Universidade do Vale do Rio dos Sinos, São Leopoldo- RS, 2011.

MORAIS, M. M. S. Comprometimento organizacional: um estudo com docentes do CEFET-MG . 2011. 123 f. Dissertação (Mestrado em Administração) - Faculdade Novos Horizontes, Belo Horizonte, 2011.

MULLER, J. M. S. Atuação dos diferentes estrategistas em uma empresa hoteleira: uma análise à luz da estratégia como prática. 2012. 170 f. Dissertação (Mestrado em Administração) Universidade Regional de Blumenau, Blumenau - SC, 2012.

NEVES, M. A. V. W. Violência e sofrimento no trabalho em profissionais de nivel gerencial: estudo de caso em uma IES. 201183 f. Dissertação (Mestrado em Administração) - Universidade Positivo, Curitiba - PR, 2011.

NICOLAI, E. F. P. Competências profissionais: um estudo com gestores do varejo de moda do "Barro Preto" - Belo Horizonte (MG). 2012. 114 f. Dissertação (Mestrado em Administração) - Faculdade Novos Horizontes - MG, 2012.

OLIVEIRA, M. A. O processo de transferência de tecnologia na pecuária leiteira: o caso do projeto balde cheio no município de Lima Duarte (MG). 2012. 96 f. Dissertação (Mestrado em Administração) - Universidade Federal de Lavras. Lavras - MG, 2012.

OLIVEIRA, M. C. Os motivos das relações entre os construtos qualidade percebida, confiança, comprometimento e lealdade na educação a distância. 2012. 156 f. Dissertação (Mestrado em Administração e Negócios) - Pontifícia Universidade Católica do Rio Grande do Sul, Porto Alegre, 2012.

PAES DE PAULA, A. P. Repensando os estudos organizacionais: por uma nova teoria do conhecimento. Rio de Janeiro: FG, 2015. 


\section{ALPERSTEDT \& SIMONE GHISI FEUERSCHÜTTE}

PASINI, K. B. Projetos de mal em aterros sanitários: contribuições das tecnologias ambientais para o desenvolvimento sustentável. 2011. 125 f. Dissertação (Mestrado em Administração) - Universidade Federal da Bahia, Salvador, 2011.

PATTON, M. Q. Qualitative research and evaluation methods. 3.ed. Thousand Oaks: Sage, 2002.

PIRES, M. G. A integração pós-fusão dos sistemas e da tecnologia da informação nas fusões e aquisições em instituições bancárias. 2011. 323 f. Tese (Doutorado em Administração) - Universidade São Paulo, São Paulo, 2011.

PONTE, F. L. F. Relacionamentos amorosos no ambiente de trabalho: estudo de caso em uma empresa brasileira. 2011. 101 f. Dissertação (Mestrado Profissional em Administração e Desenvolvimento Empresarial) - Universidade Estácio de Sá, Rio de Janeiro, 2011.

REIS, P. N. C. Os fatores que explicam o grau de aceitação de um sistema de informação acadêmica (SIA) utilizados no processo de apoio à gestão docente: um estudo de caso numa ies privada. 2011129 f. Dissertação (Mestrado Profissional em Administração e Desenvolvimento Empresarial) - Universidade Estácio de Sá, Rio de Janeiro, 2011.

RICHARDSON, L. S. T.; PIERRE, E. A. Writing: A Method of Inquiry. In: DENZIN, N. K.; LINCOLN, Y. S. (Eds.). Handbook of Qualitative Research. Thousand Oaks, CA: Sage, 1994. p. 516-529.

SANTOS, C. A. F. A gestão de resíduos eletroeletrônicos e suas consequências para a sustentabilidade: um estudo de múltiplos casos na região metropolitana de Porto Alegre. $2012131 \mathrm{f}$. Dissertação (Mestrado em Administração) - Universidade Federal do Rio Grande do Sul - RS, Porto Alegre, 2012.

SARPA, R. Compartilhamento e transferência do conhecimento na nacionalização de material de defesa: estudo de caso. 2011. 109 f. Dissertação (Mestrado Profissional em Administração e Desenvolvimento Empresarial) - Universidade Estácio de Sá, Rio de Janeiro, 2011.

SERVA, M. Prefácio. In: PAES DE PAULA, A. P. Repensando os estudos organizacionais: por uma nova teoria do conhecimento. Rio de Janeiro: FG, 2015.

SILVA, J. A. F. Análise do sistema integrado de contabilidade (SIC) sob a ótica do controle externo: estudo no tribunal de contas do Estado do Ceará. 2012. 134 f. Dissertação (Mestrado Profissional em Administração e Controladoria) - Universidade Federal do Ceará, Fortaleza, 2012.

SILVA, J. A. R. A permanência de alunos nos cursos presenciais e a distância de administração: contribuições para gestão acadêmica. 2012. 273 f. Tese (Doutorado em Administração) Fundação Getúlio Vargas/RJ, Rio de Janeiro, 2012.

SILVA, M. A. Estresse e Burnout: um estudo com professores do CEFET-MG. 2011. $144 \mathrm{f}$. Dissertação (Mestrado em Administração) - Faculdade Novos Horizontes, Belo Horizonte, 2011.

SILVA, N. Q. A. Análise institucional do conceito de reservas extrativistas: perspectiva dos atores sociais em Rondônia. 2012. 103 f. Dissertação (Mestrado em Administração) - Universidade Federal de Rondônia, Porto Velho, 2012. 
STAKE, R. E. Qualitative case studies. In: DENZIN, N. K.; LINCOLN, Y. S. (Eds.). The Sage Handbook of qualitative research. 4.ed. Thousand Oaks: Sage, 2005. p. 443-466.

Penso, 2011.

. Pesquisa Qualitativa: estudando como as coisas funcionam. Porto Alegre:

TEIXEIRA, J. C.; NASCIMENTO, M. C. R.; CARRIERI, A. de P. Triangulação entre métodos na administração: gerando conversações paradigmáticas ou meras validações "convergentes"? Revista de Administração Pública, v. 46, n. 1, p. 191-220, 2012.

TEIXEIRA, J. C.; NASCIMENTO, M. C. R.; ANTONIALLI, L. M. Perfil de estudos em Administração que utilizaram triangulação metodológica: Uma análise dos Anais do EnANPAD de 2007 a 2011. Rev. Adm., v. 48, n. 4, p. 800-812, out./nov./dez. 2013.

TOLEDO, M. P. Participação de instituições locais em projetos de revitalização urbana: o caso do Projeto Porto Maravilha na Cidade do Rio de Janeiro. 2012. 113 f. Dissertação (Mestrado em Administração) - Fundação Getúlio Vargas/RJ, Rio de Janeiro, 2012.

VASCONCELOS, A. C. V. H. Gênero e economia solidária: um olhar sobre a participação e atuação das mulheres nas organizações do terceiro setor. 2011. 189 f. Dissertação (Mestrado em Administração) - Universidade Federal de Uberlândia, Uberlândia - MG, 2011.

VELOSO E SOUZA, C. Neurociências e marketing: explorando fronteiras diádicas e integrando metodologias para compreensão do comportamento do consumidor. 2012. 317 f. Tese (Doutorado em Administração) - Universidade Federal de Minas Gerais, Belo Horizonte, 2012.

WEBER, T. Gestão da saúde e segurança do trabalho na indústria petroquímica: um estudo de caso. 2012. 156 f. Dissertação (Mestrado em Administração) - Universidade Federal do Rio Grande do Sul - RS, Porto Alegre, 2012.

ZAPPELLINI, M. B.; FEUERSCHÜTTE, S. G. O uso da triangulação na pesquisa científica brasileira em administração. Administração: Ensino e Pesquisa, v. 16, n. 2, p. 241-273, 2015. 


\section{ALPERSTEDT \& SIMONE GHISI FEUERSCHÜTTE}

\section{DADOS DOS AUTORES}

\section{ALFREDO RIBEIRO CÁRDENAS ${ }^{\star}$ alfredo.ribeiro@ifsc.edu.br}

\section{Mestre em Administração pela UDESC}

Instituição de vinculação: Instituto Federal de Santa Catarina

Gaspar/SC - Brasil

Áreas de interesse em pesquisa: Educação empreendedora; Ensino e Pesquisa em Administração.

^Rua Adriano Korman, 510 Bela Vista Gaspar/SC 89110-971

\section{TIAGO DA COSTA tiago.costa@uffs.edu.br}

\section{Mestre em Administração pela UDESC}

Instituição de vinculação: Universidade Federal da Fronteira Sul

Laranjeiras do Sul/PR - Brasil

Áreas de interesse em pesquisa: Desenvolvimento Territorial; Sustentabilidade; Inovação Social.

\section{GRAZIELA DIAS ALPERSTEDT gradial@gmail.com}

\section{Doutora em Engenharia de Produção e Sistemas pela UFSC}

Instituição de vinculação: Universidade do Estado de Santa Catarina Florianópolis/SC - Brasil

Áreas de interesse em pesquisa: Organizações, Sustentabilidade e Inovação Social; Ensino e Pesquisa em Administração.

\section{SIMONE GHISI FEUERSCHÜTTE ghisi.simone@gmail.com}

\section{Doutora em Engenharia de Produção e Sistemas pela UFSC}

Instituição de vinculação: Universidade do Estado de Santa Catarina Florianópolis/SC - Brasil

Áreas de interesse em pesquisa: Subjetividade nas Organizações; Gestão de Pessoas e Comportamento Humano nas Organizações; Métodos Qualitativos em Administração. 